\title{
COXA PLANA: A RADIOLOGICAL COMPARISON OF THE RATE OF HEALING WITH CONSERVATIVE MEASURES AND AFTER OSTEOTOMY
}

\author{
Tage Marklund and Bengt Tillberg, Linköping, Sweden \\ From the Departments of Diagnostic Radiology and of Orthopaedic Surgery. \\ Regional Hospital, Linköping
}

\begin{abstract}
Subtrochanteric osteotomy has been reported to interrupt the destructive phase of coxa plana and speed up the rate of healing. The aim of this investigation was to test the validity of these statenients. The material comprised twenty-five patients treated by osteotomy and thirty-three patients treated by support in a Thomas's splint. For every patient the extent of the radiological changes was estimated and plotted against time as a percentage of the normal epiphysial volume. The graph so obtained represents the rate of destruction and re-ossification, as well as the maximum involvement of the epiphysis. The curves for each group of patients were superimposed in a graph with all the minima coincident in time. The two patterns of curves are closely similar. It was confirmed statistically that the rates of destruction and re-ossification did not differ between the two groups. The results afford no evidence that osteotomy interrupts the disease or speeds up healing.
\end{abstract}

Since 1965 a number of authors have presented impressive results obtained with subtrochanteric derotation and varus osteotomy in the treatment of coxa plana (Axer 1965; Chapchal 1967; Girod 1969; Hördegen and Witt 1971; Zweymüller 1972). The theory underlying this surgical procedure is that if the femoral head is completely covered by the roof of the acetabulum it will be moulded into a more normal form and weight-relieving treatment can be abandoned.

The operation is also considered to arrest the progress of the disease. Axer (1965) wrote: "Operation seems to interrupt the destructive phase and start the joint on its way to reconstruction", and again (Axer and Schiller 1973): "The normal pumping action of the unrestricted pelvifemoral muscles may accelerate revascularisation and in this way decrease the time of the disease process."

The aim of the present study was to test the validity of these statements. The radiological course of coxa plana in a series of patients treated conservatively (weight relief) and another treated by operation (osteotomy) has been represented graphically by a method used earlier by Ponseti and Cotton (1961) in an attempt to determine the rate of re-ossification of the epiphysis in patients with coxa plana treated with L-triiodothyronine.

\section{MATERIAL}

This method of analysis was applied in two series of cases. The first comprised twenty-six hips in twenty-five patients who underwent subtrochanteric osteotomy with derotation and varus angulation at the Hospital of Orthopaedic Surgery, Härnösand. The operation was followed by two months in a plaster splint. (Some of the cases in this treatment group have been reported earlier by Haraldsson (1973).) The second series consisted of twenty-three hips in twenty-two patients at the Department of Orthopaedic Surgery, Regional Hospital, Linköping; these patients received conservative treatment on fairly traditional lines, with some weeks of bed rest and application of a Thomas's splint until the end of the destructive phase. The weight relief lasted for one to two years.

The age distributions differ for the two series (Fig. 1). The ages in the osteotomy group ranged from two to ten years (mean 5.2 years), and in the conservatively treated group from four to eleven years (mean 6.4 years). The extent of involvement of the epiphysis at the time of diagnosis (the first radiograph) was greater in the osteotomy group (Fig. 2). This may be because the group receiving conservative treatment came from a more urbanised area and the patients would probably have been seen earlier, on average, than those in the osteotomy group.

\section{METHOD}

For every patient the radiological changes in the femoral head were estimated from frontal and lateral radiographs and plotted against time as a percentage of the normal epiphysial volume. When re-ossification had started the extent of the normal spongiosa was likewise estimated. The graph so obtained represents the rate of destruction, the rate of re-ossification and the extent to which the epiphysis is involved.

The determination is, of course, fairly rough and

Dr Tage Marklund, The Department of Diagnostic Radiology, The Medical School, Linköping University, Regional Hospital, S-581 85 Linköping, Sweden.

Dr Bengt Tillberg, Department of Orthopaedic Surgery, Regional Hospital, S-581 85 Linköping, Sweden. 
subject to error; the accuracy is not enhanced by measurements of the irregularly distributed changes on the radiographs. However, taken together the graphs will serve their purpose.

A typical graph is shown in Figure 3. The descending

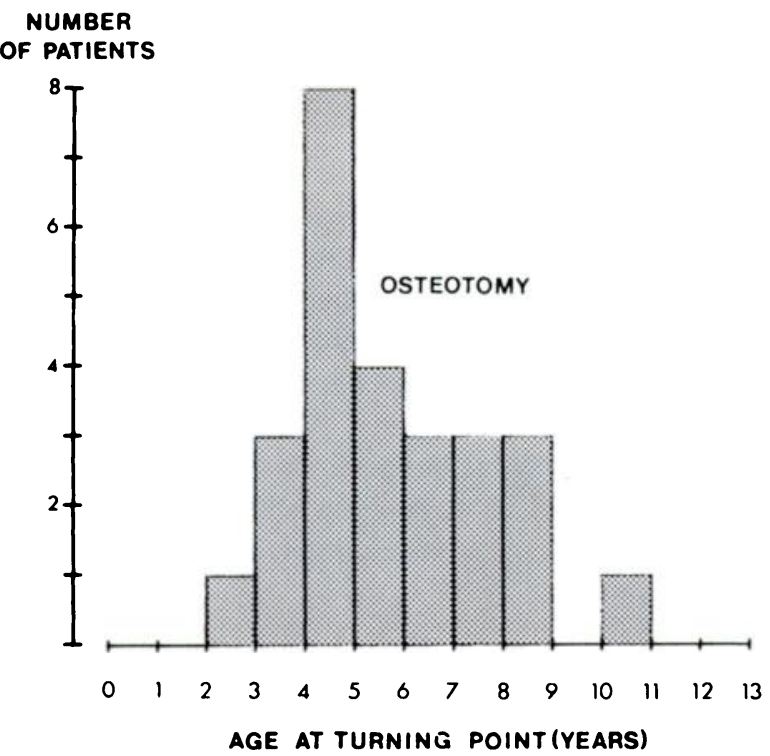

Fig. 1

Age distribution of the two treatment groups at the turning point.

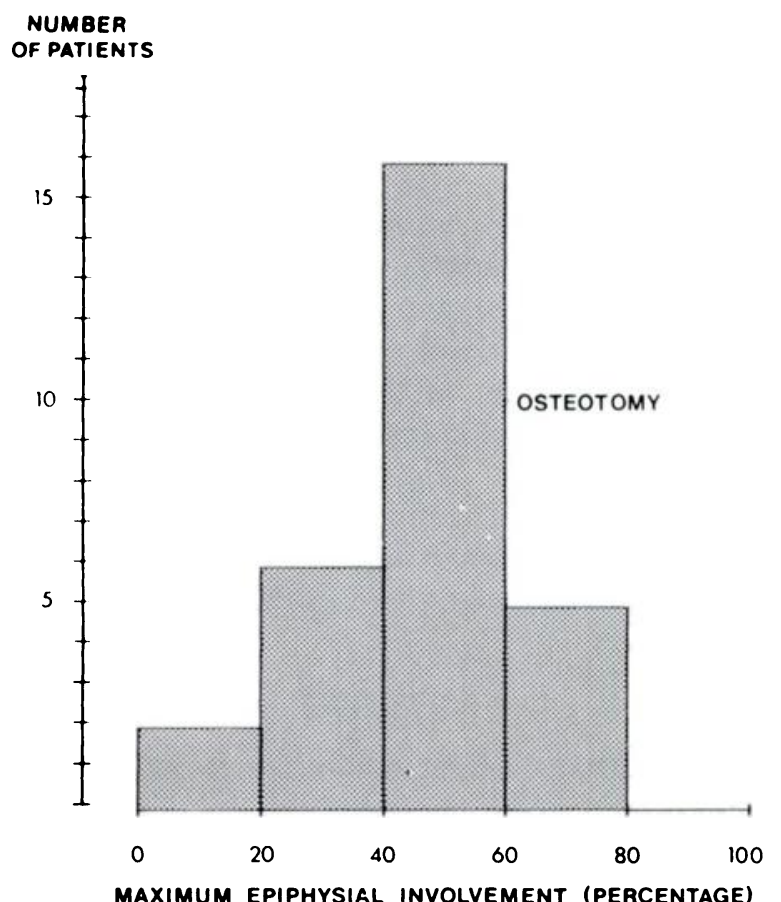

FiG. 2

Epiphysial involvement at the time of diagnosis in the two groups.

and ascending portions of the curve are approximately linear. At the minimum, destruction changes to reossification. When the lowest part of the curve is horizontal, the turning point is presumably in the middle of the horizontal segment.
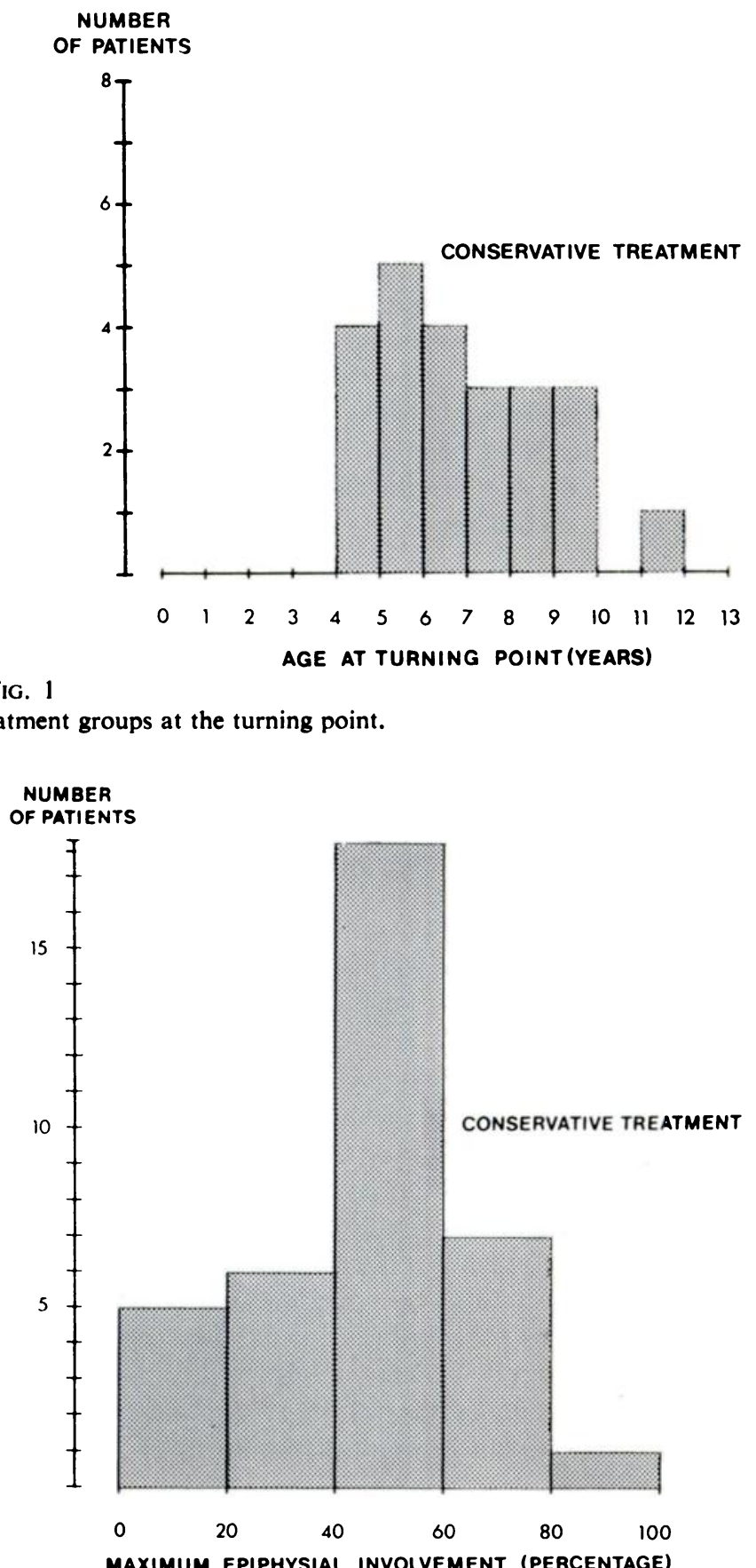

The slopes of the regression lines from the turning points to the first and last values - that is, the tangents of the angles $\alpha$ and $\beta$-provide a measure of the rate of destruction and re-ossification, respectively, as represented by the percentage loss or gain of normal epiphysial

MAXIMUM EPIPHYSIAL INVOLVEMENT (PERCENTAGE) spongiosa per year. The mean and standard deviations were calculated.

The duration of the disease was measured from the time that conspicuous alterations were visualised in the radiographs to the time that the epiphysis was re-ossified 
with not more than 25 per cent of it involved by the residual defect. Mean and standard deviations were calculated.

\section{RESULTS}

The comprehensive graph-The curves for each group of patients were superimposed in a graph with all the turning groups, even if the rate of re-ossification seems to be slightly higher in the osteotomy group. 4) Although there is a large variation in the total healing time, it is much the same in the two groups. When there is a more extensive involvement of the epiphysis, complete reossification takes longer, but the rate of re-ossification would seem not to be slower.

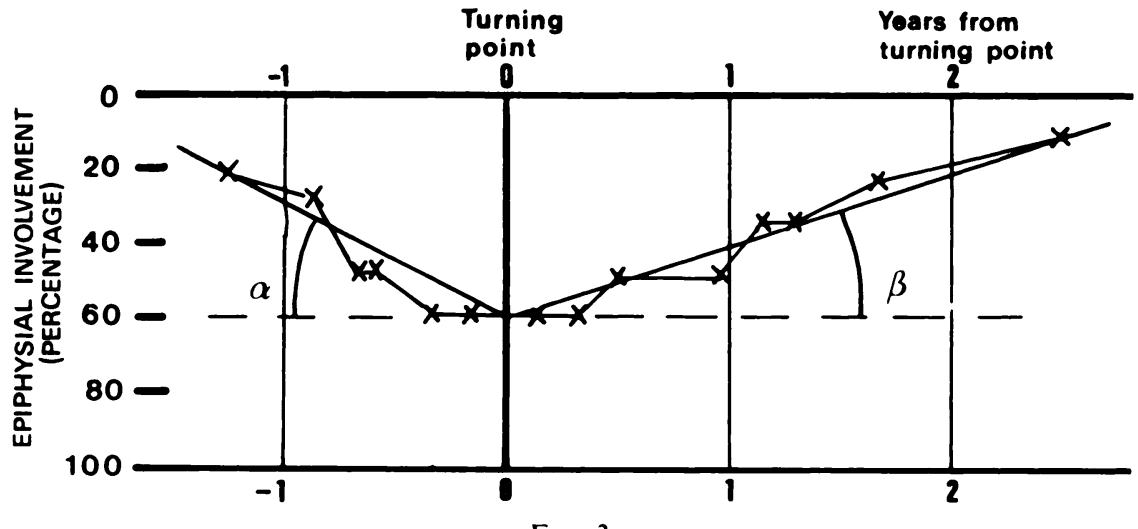

FIG. 3

Typical graph for a patient, showing the rate of destruction and re-ossification. Destruction changes to recovery at the minimum of the curve. The rates of destruction and reossification are represented by the tangents of the angles $\alpha$ and $\beta$ respectively.

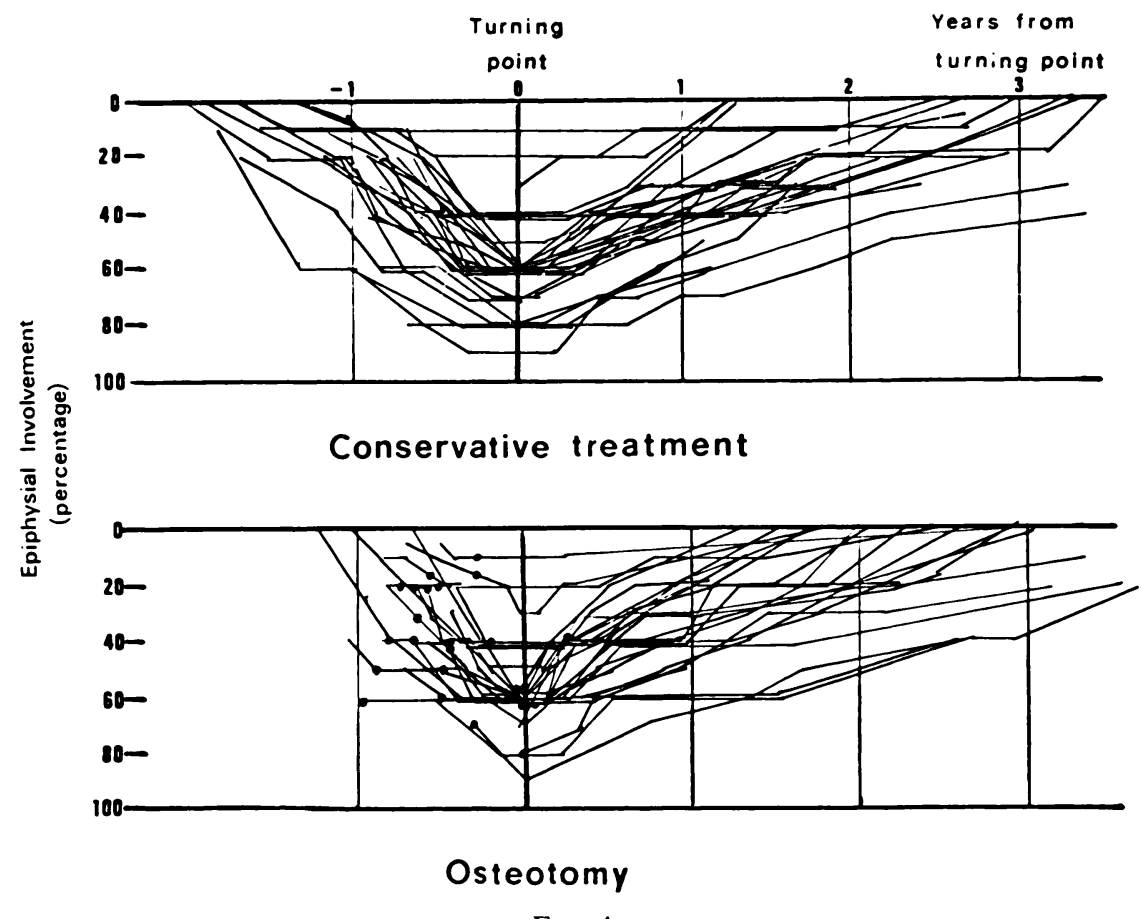

FiG. 4

The curves of each group superimposed, with the minima lying on a vertical line, through the time axis.

points (minima) coincident in time-that is to say, they all lie on a perpendicular to the time axis (Fig. 4). From a visual inspection of the assembled curves it is seen that: 1) the two patterns of superimposed curves are closely similar; 2) the variation is large in both groups; 3 ) the slopes representing the rates of destruction and re-ossification do not differ greatly between the two
Epiphysial involvement-The distributions of maximum epiphysial involvement were similar in the two groups (Fig. 5).

Correlations-In six graphs the rate of destruction and re-ossification, maximum epiphysial involvement and age at the turning point were plotted. There was a weak correlation between age and the rate of re-ossification. 
The correlation coefficients were -0.23 for the osteotomy group and -0.21 for the conservatively treated group.

Statistical analysis-The mean and the standard deviations of the rates of destruction and re-ossification were calculated as a percentage of epiphysial bone destroyed as judged on the criteria applied. The slightly higher rate of re-ossification in the osteotomy group can be attributed to the age distribution. The shorter duration of the disease in that group is probably attributable to the later discovery of the disease in these patients.
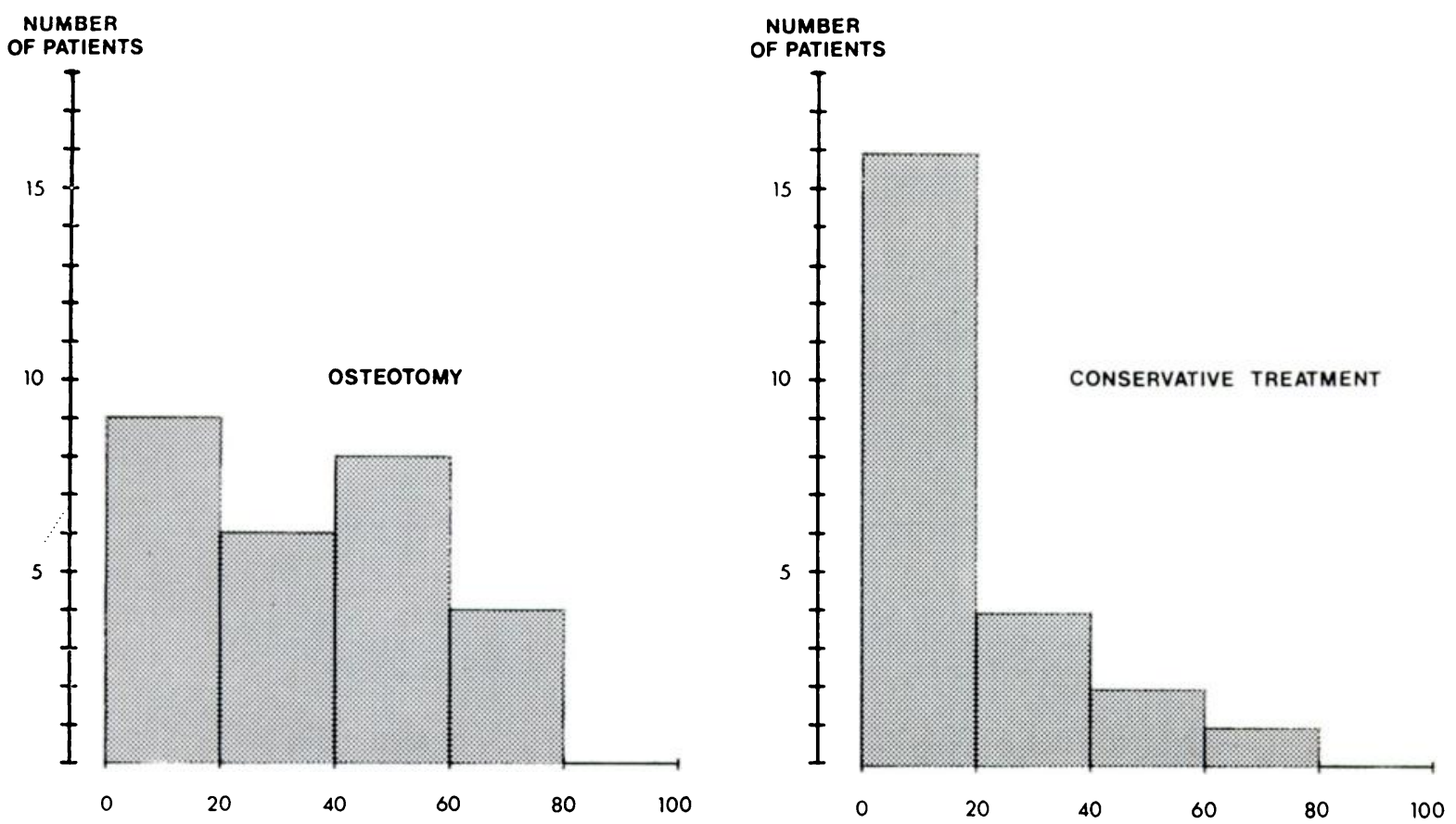

EPIPHYSIAL INVOLVEMENT AT TIME OF DIAGNOSIS (PERCENTAGE) EPIPHYSIAL INVOLVEMENT AT TIME OF DIAGNOSIS (PERCENTAGE)

FIG. 5

Distribution of maximal epiphysial involvement in the two groups.

or re-ossified per year (Fig. 6). The differences between the two forms of treatment are not statistically significant (Table I).

Mean and standard deviations for the duration of the disease were calculated. For the group receiving conservative treatment it was 3 years 2 months \pm 1 year 8 months, and for the osteotomy group it was 2 years 9 months. Because of the large variation in the two groups the difference is not statistically significant.

TABLE I

Rates of Destruction and Re-ossification in the Two Trfatment Groups

\begin{tabular}{|c|c|c|c|c|}
\hline & \multicolumn{2}{|c|}{$\begin{array}{l}\text { Rate of destruction } \\
\text { (percentage decrease } \\
\text { in normal epiphysial } \\
\text { bone per year) }\end{array}$} & \multicolumn{2}{|c|}{$\begin{array}{c}\text { Rate of re-ossification } \\
\text { (percentage increase } \\
\text { in normal epiphysial } \\
\text { bone per year) }\end{array}$} \\
\hline & Mean & $\begin{array}{l}\text { Standard } \\
\text { deviation }\end{array}$ & Mean & $\begin{array}{l}\text { Standard } \\
\text { deviation }\end{array}$ \\
\hline $\begin{array}{l}\text { Conservative } \\
\text { treatment }\end{array}$ & 38 & 9 & 22 & 8 \\
\hline Osteotomy & 39 & 9 & 24 & 8 \\
\hline
\end{tabular}

\section{DISCUSSION}

There was no evident difference in the course of coxa plana after osteotomy and after conservative treatment
The two kinds of treatment would thus appear to be either equally good, equally bad or equally futile. If equally good or bad, it is remarkable that the delay in the treatment in the osteotomy group is not reflected in the results. The evidence seems to suggest that the course of the disease was uninfluenced by either form of treatment.

It is evident that surgical intervention neither shortened the re-ossification time nor interrupted the destruc-
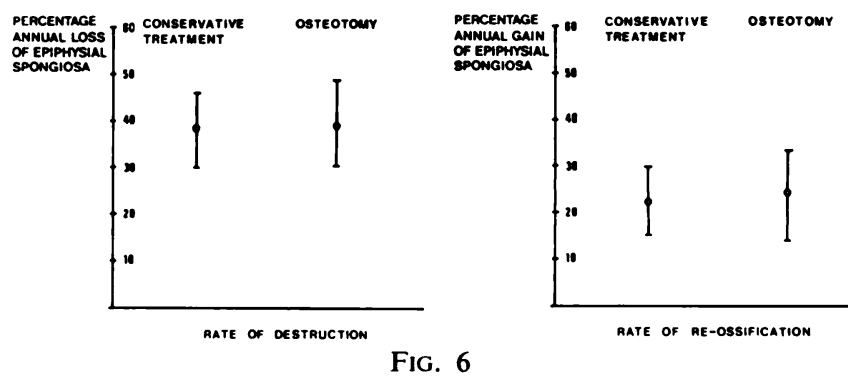

Rates of destruction and re-ossification.

tive phase. In fact, in many patients the deterioration continued for a considerable period after operation.

The appearances of coxa plana are many and diverse, and numerous classifications have been proposed. Legg (1927) made a division into "cap" and "mushroom" 
types. Other groupings have been based on the extent of the involvement of the epiphysis (Goff 1954; O'Garra 1959; Ferguson 1963; Catterall 1971). From the present

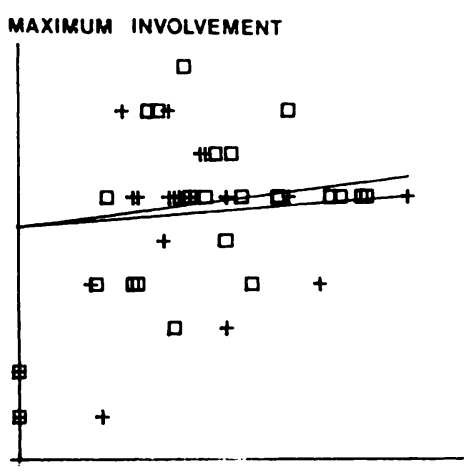

RATE OF RE-OSSIFICATION

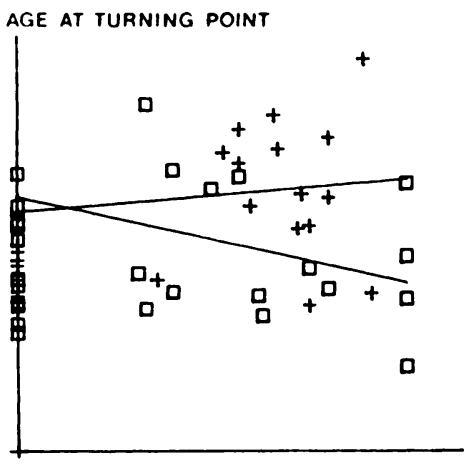

RATE OF DESTRUCTION

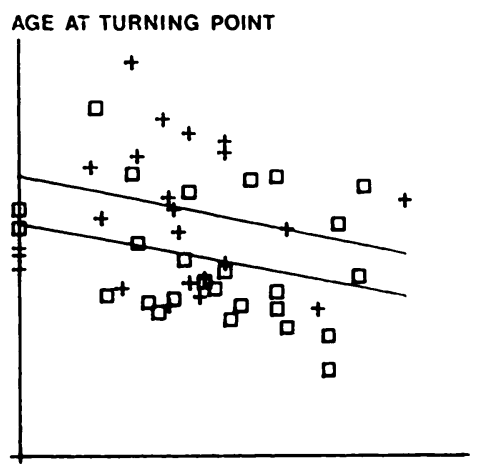

RATE OF RE-OSSIFICATION

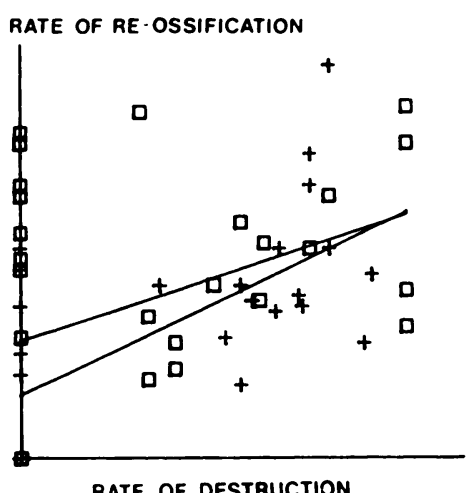

Fig. 7 known that at the turning point when the involvement is at its maximum, there is a fairly strong correlation between the degree of involvement and the anatomical endRates of destruction and re-ossification versus maximum epiphysial involvement and age at turning point. Rate of re-ossification
versus rate of destruction. Age at turning point versus maximum epiphysial involvement. + ostetomy. $\square$ conservative treatment. The lines in the graphs are regression lines.

study it seems that there are no specific types or welldemarcated classes of the condition, but that there is rather a continuous distribution of the extent of epiphysial involvement. The distribution of the extent of maximum involvement is evidently bell-shaped, with a mean maximum involvement of about one-half of the epiphysial volume. This is consistent with the results reported by Chung and Moe (1965). result (Goff 1954; Ponseti 1956; O’Garra 1959; Ralston 1961 ; Ferguson 1963; Chung and Moe 1965; Sanders and MacEwen 1969; Catterall 1971). Accordingly, the schematic model, which shows the distribution of the maximum involvement in a number of cases, helps to explain the familiar fact that the outcome for a particular patient is related to the stage at which the disease is discovered. The closer to the turning point the disease

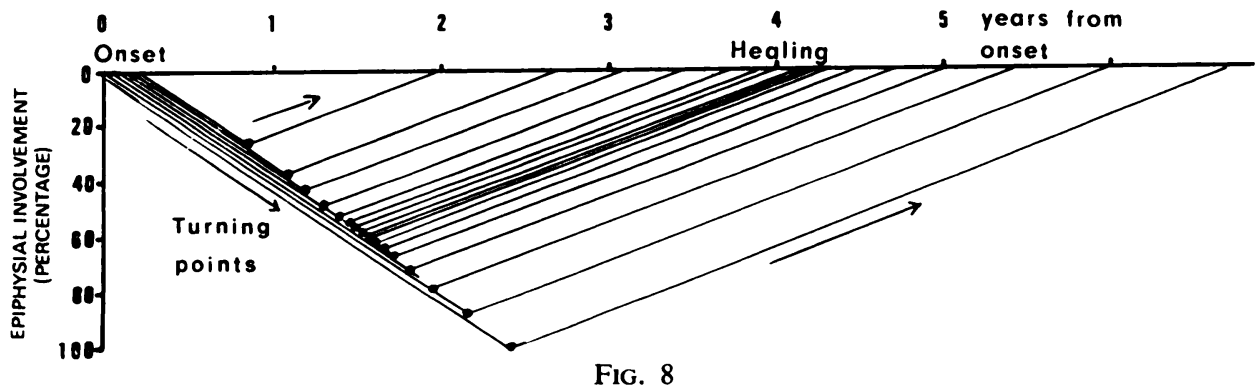

Simplified model representing the course of the disease in a number of patients.

The curve pattern in the two series can be represented schematically (Fig. 7) and the resulting graph could be used as a model to illustrate the course of the disease in the present material (Fig. 8). If neither treatment influences the course of the disease, such a model might be applicable not only to the present material, but also to the course of the disease without treatment. It is well is discovered, the greater the prognostic significance of the stage at discovery.

Conclusion-The results of this study afford no evidence that osteotomy has any better or worse effect on the course of coxa plana than conservative treatment. In fact, it seems very likely that neither of the two treatments influences the course of the disease. 


\section{REFERENCES}

Axer, A., Schiller, M. G., Segal, D., Rzetelny, V., and Gershuni-Gordon, D. H. (1973) Subtrochanteric osteotomy in the treatment of Legg-Calvé-Perthes' syndrome. Acta orthopaedica Scandinavica, 44, 31-54.

Catterall, A. (1971) The natural history of Perthes' disease. Journal of Bone and Joint Surgery, 53-B, 37-53.

Chapchal, G. (1967) Uber die Derotations-Varisation-Osteotomie bei der Perthes`schen Krankheit. Verhandlungen der Deutschen Orthopädischen Gesellschaft, 54, 208.

Chung, S. M. K., and Moe, J.H. (1965) Legg-Calvé-Perthes disease: clinical-radiographic correlations. Clinical Orthopaedics and Related Research, 41, 116-124.

Ferguson, A. B., Jun. (1963) Orthopedic Surgery in Infancy and Childhood. Second edition. Baltimore: Williams and Wilkins.

Girod, G. (1969) Die varisierande intertrochantere Derotationsosteotomie bei der Perthesschen Erkrankung. Beiträge zulr Orthopädie und Traumatologie, 16, 419-425.

Goff, C. W. (1954) Legg-Calvé-Perthes S!ndrome and Related Osteochondroses of Youth. Springfield, Illinois: Charles C. Thomas.

Haraldsson, S. (1973) Derotation varisation osteotomy in the treatment of Perthes' disease. Acta orthopaedica Scandinavica, 44, 105-108.

Hördegen, K. M., and Witt, A. N. (1971) Erfahrungen mit der intertrochanteren Varisierungsosteotomie tei der Legg-Calvé-Perthes' schen Erkrankung. Archiv für orthopädische und Unfall-Chirurgie, 70, 320-339.

Legg, A. T. (1927) The end results of coxa plana. Journal of Bone and Joint Surgery, 9, 26-36.

O'Garra, J. A. (1959) The radiographic changes in Perthes' disease. Journal of Bone and Joint Surgery, 41-B, 465-476.

Ponseti, I. V. (1956) Legg-Perthes disease. Journal of Bone and Joint Surgery, 38-A, 739-750.

Ponseti, I. V., and Cotton, R. L. (1961) Legg-Calvé-Perthes disease-pathogenesis and evolution. Journal of Bone and Joint Surgery, 43-A, 261-274.

Ralston, E. L. (1961) Legg-Calvé-Perthes disease-Factors in healing. Journal of Bone and Joint Surgery, 43-A, 249-260.

Sanders, J. A., and MacFwen, G. D. (1969) A long-term follow-up on coxa plana at the Alfred I. DuPont Institute. Southern Medical Journal, 62, 1042-1047.

Zweymüller, K. (1972) Zur operativen Behandlung des Morbus Perthes. Wiener medizinische Wochenschrift, 122, 440-444. 